\title{
Medijatizacija religije u kontekstu religijske transformacije
}

Željko Pavić*

zpavic@kulturologija.unios.hr
UDK: $2: 316.74$ “ 20 “

Pregledni članak / Review Primljeno: 21. travnja 2016. Prihvaćeno: 8. lipnja 2016.

U ovome se radu aktualna teza o medijatizaciji religije pokušava staviti u kontekst teorija koje pokušavaju objasniti kretanje religioznosti i položaja religije u suvremenim društvima. Današnja se situacija stavlja u kontekst transformacije religije te se analizira na koji način medijatizacija religije utječe na taj kontekst. Time se medijatizacija promatra kao proces koji se nalazi pod utjecajem transformacije religije, ali i kao djelomično neovisan proces koji utječe na religijsku transformaciju potičući specifičan duhovni pluralizam i individualizam (post) modernih zapadnih društava u kojemu se pojavljuju nove, eklektične forme religioznosti. U tom se smislu osobito analizira pitanje utjecaja medijatizacije na osporavanje religijskih autoriteta te internet kao nov medij koji svojom decentraliziranošću ima potencijalno jak utjecaj na transformaciju religije i religijskih autoriteta. Zaključuje se da je medijatizacija vrlo složen i dvostran proces čije se značenje i doseg ne bi trebali prenaglašavati jer mnogim situacijama medijsko posredovanje religije služi samo kao pojačavanje postojećih teritorijalnih, licemu-lice religijskih zajednice te se nalazi pod kontrolom formalnih religijskih vođa. Ključne riječi: medijatizacija, transformacija religije, sekularizacija, internet, socio-cultural changes.

\footnotetext{
* Doc. dr. sc. Željko Pavić, Odjel za kulturologiju Sveučilišta Josipa Jurja Strossmayera u Osijeku, Trg Svetog Trojstva 3, HR-31000 Osijek.
} 


\section{Uvod}

Pitanje medija i medijski posredovanih religijskih sadržaja rijetko je prisutno u dosadašnjim i još uvijek živahnim raspravama o sekularizaciji suvremenih društava. Većina je dosadašnjih priloga toj raspravi implicitno pretpostavljala da su mediji neutralan prenositelj dominantnih društvenih ideologija, bile one sekularističke ili prožete religijom. U tom se smislu rijetko postavljalo istraživačko pitanje o tomu na koji način i koliko mediji aktivno i više ili manje samostalno prenose religijske sadržaje, djeluju li kao nositelji sekularne svijesti ili mogu doprinijeti desekularizirajućim procesima i trendovima te koji su mehanizmi takvih utjecaja. Takvo istraživačko pitanje činilo bi doprinos polemici između onih koji smatraju da je sekularizacija stvaran proces i onih koji je osporavaju. Iako uloga medija u pravilu nije posebno problematizirana kod teoretičara sekularizacije, implicitna je pretpostavka da su mediji jedni od nositelja sekularne javne sfere, odnosno sukreatori svijeta modernosti. $\mathrm{Na}$ drugoj se razini otvara analitički različito istraživačko pitanje o tomu na koji način mediji utječu na transformaciju religije, osporavanje ili učvršćivanje religijskih autoriteta, odnosno na način na koji vjernici doživljavaju religiju i odnošenje prema transcendentnom. Posljednjih je godina u tom kontekstu osobito aktualna i konceptualno plodna teza o tzv. medijatizaciji religije. Cilj je ovoga rada pokušati spojiti ove dvije teorijsko-istraživačke tradicije, donekle odvojene i činjenicom da se u prvoj tradiciji uglavnom mogu pronaći sociolozi, a u drugoj znanstvenici iz područja informacijskih i komunikacijskih znanosti. Dakle, pokušat ćemo pokazati da se uloga medija u transformaciji religije u suvremenom svijetu ne može promatrati kao nusprodukt drugih važnijih procesa (sekularizacije, »oživljavanja« religije ili njezine istaknute javne uloge), nego da se medijatizacija može i treba shvatiti kao proces koji je isprepleten s navedenim procesima. S druge strane, medijatizacija je proces koji se također u potpunosti može objasniti samo ako ga se stavi u kontekst širih društvenih i kulturnih promjena i uloge transformacije religije unutar njih.

\section{Sociokulturne promjene i transformacija religije}

Debate o sekularizacije počele su od samog nastanka sociologije religije i srodnih disciplinarnih tradicija unutar društvenih i humanističkih znanosti. Različiti oblici teorije sekularizacije sve do 1990-ih činile su dominantnu paradigmu za tumačenje kretanja religije i religioznosti u suvremenim društvima. Teorija sekularizacije bila je usko povezana s teorijom modernizacije pa su i različiti autori naglašavali različite modernizacijske čimbenike i njihov utjecaj na pad religioznosti i društvene važnosti religije. Tako je jedan od začetnika ove 
teorije Bryan Wilson sekularizaciju povezao s procesom tzv. socijetalizacije. ${ }^{1}$ Naime, nastanak industrijskog društva doveo je do smanjenja važnosti morala kao integrativnog društvenog načela koje je bilo važno u malim lokalnim zajednicama u kojim se osobna vjerodostojnost dokazivala upravo moralnim kvalitetama koje su bile vidljive iz svakodnevne komunikacije. S druge strane, industrijsko društvo dovodi do nastanka velikih gradova u kojima se djelomično gube ovakvi mehanizmi socijalne kontrole, a postindustrijalizacijom se društveni poredak pretvara u tehničku kontrolu impersonalnih uloga koja dovodi do »de-moralizacije« društva. Jedan od najvažnijih zagovornika teorije sekularizacije, Steve Bruce, uzroke sekularizacije vidi u promjenama u »generalnoj kulturi« (razvoj tehnologije koji omogućava kontrolu nad prirodom), promjenama društvenih institucija (funkcionalna diferencijacija) i promjenama vezanim uz socijalnu psihologiju (relativizacija svjetonazora povezana sa sve češćim susretima s ljudima drukčijih svjetonazora). ${ }^{2}$

Norris i Inglehart analiziraju podatke iz Svjetskog istraživanja vrednota (WVS) te opadajući stupanj religioznosti povezuju s rastućim razinama egzistencijalne sigurnosti do kojih dovodi modernizacija, tj. rast ekonomskog blagostanja. ${ }^{3}$

$S$ vremenom se, uglavnom pod pritiskom empirijskih podataka koji ukazuju na neravnomjerno opadanje religioznosti i vrlo različite društvene uloge religije u podjednako (ne)moderniziranim zemljama, pojavljuje kritike teorije sekularizacije, kao i teorije koje je pokušavaju dopuniti ili se prikazati kao posve nova alternativa.

Već i Inglehart i Norris upozoravaju da se prilikom analiziranja društvenih vrijednosti, pa tako i religioznosti, u obzir moraju uzimati različita sociokulturna i povijesna nasljeđa koja djeluju »ometajuće« na linearne prognoze teorije modernizacije. Ovakva se nasljeđa očituju i u činjenici da je religioznost u nekim slučajevima znatno veća od onoga što bi se moglo očekivati na temelju stupnja modernizacije. Sjedinjene Američke Države dobar su primjer zemlje u kojoj je specifično povijesno nasljeđe uzrokovalo istovremeno postojanje visoke razine religijskog pluralizma i funkcionalnu diferencijaciju društvenih institucija, ali visoku razinu religioznosti mjerenu različitim indikatorima (konfesionalna identifikacija, religijska praksa, religijska vjerovanja i sl.). Slično tomu, Ringvee empirijskom analizom konfesionalne identifikacije u zemljama Istočne i Srednje Europe ukazuje na činjenicu da se visoka razina konfesionalne iden-

\footnotetext{
${ }^{1}$ Vidjeti, primjerice, Bryan R. WILSON, Religion in Secular Society, Harmondsworth, Penguin Books, 1966. ili Bryan R. WILSON, Salvation, Secularization, and De-moralization, u: Richard K. Fenn (ur.), The Blackwell Companion to Sociology of Religion, Malden, Blackwell Publishing, 2003, 39-51.

2 Usp. Steve BRUCE, The secularisation of Scotland, International Journal for the Study of the Christian Church, 14 (2014) 2, 193-206.

${ }^{3}$ Usp. Ronald INGLEHART, Pippa NORRIS, Sveto i svjetovno. Religija i politika u svijetu, Zagreb, Politička kultura, 2007.
} 
tifikacije može primijetiti u zemljama u kojima je religija igrala važnu ulogu u nacionalnim pokretima, odnosno tamo gdje religija čini važnu sastavnicu nacionalnog identiteta (npr. Hrvatska i Poljska). Tamo gdje pripadnici jedne nacije u potpunosti ne dijele i religijsku pripadnost (npr. Mađarska) ili nacionalna crkva nije igrala važnu ulogu u nacionalnom pokretu (npr. Latvija) i stupanj konfesionalne identifikacije znatno je niži. ${ }^{4}$ Upravo ovakvi empirijski nalazi dovode i do novih konceptualizacija, poput onih o višestrukim modernostima ${ }^{5}$ ili višestrukim sekularnostima. ${ }^{6}$

S druge strane, tzv. teorija religijskih ekonomija, ${ }^{7}$ američke provenijencije, nastoji pokazati da se kretanje religioznosti može objasniti strukturom religijske ponude, pretpostavljajući da će religijska potražnja postojati uvijek jer religija služi kao pružatelj tzv. psiholoških kompenzatora. Drukčije rečeno, granične životne situacije, poput bolesti ili smrti, uvijek će zahtijevati objašnjenje i utjehu koju, između ostalih, može pružiti i religija. U situacijama u kojima je ponuda strukturirana monopolistički, religioznost će biti niža. Tamo gdje postoji raznolikost religijske ponude, svaki će »kupac« religijskih usluga moći pronaći »robu« koja ga zadovoljava, pa će i religioznost biti viša. Međutim, ambiciozna sveobuhvatnost ovoga pristupa može se dovesti u pitanje s obzirom na to da teorija jednostavno ne odgovara stvarnosti, osobito kada su u pitanju europske države. ${ }^{8}$ Osim toga, ovakav se teorijski pristup isključivo usredotočuje na stupanj religioznosti pojedinaca, a ne na cjelokupan sociokulturni kontekst u kojemu se religija nalazi i koji može značajno utjecati na različite društvene uloge i društveni i politički utjecaj religije.

K tome, postoji i dodatna istraživačka tradicija koja kretanje religioznosti ne promatra kroz rast ili opadanje religije, nego kroz njezinu transformaciju. Tako, prema Lindi Woodhead, kršćanstvo u zapadnim zemljama prolazi kroz proces transformacije koji obilježava odmak od autoriteta prema individualnosti, a ovaj je proces dio postmoderne kulture u kojoj su sve meta-naracije izgubile dobar dio svoje uvjerljivosti. ${ }^{9}$ Stoga je, kako kaže Năstuță, »danas religija postala javni, komodificirani, terapeutski i personalizirani skup aktivnosti više nego što je to bila u prošlosti «. ${ }^{10}$ Wade Roof razlikuje »bivanje« $\mathrm{i}$ »potragu«

${ }^{4}$ Usp. Ringo RINGVEE, Religion. Not declining but changing. What do the population censuses and surveys say about religion in Estonia?, Religion, 44 (2014) 3, 502-515.

${ }^{5}$ Usp. Shmuel Noah EISENSTADT, The Reconstruction of Religious Arenas in the Framework of 'Multiple Modernities', Millennium - Journal of International Studies, 29 (2000) 3, 591-611.

${ }^{6}$ Usp. Monika WOLHLRAB-SAHR, Marian BURCHARDT, Multiple Secularities. Toward a Cultural Sociology of Secular Modernities, Comparative Sociology, 11 (2012) 875-909.

7 Vidjeti, primjerice, Rodney STARK, William Sims BAINBRIDGE, $A$ Theory Of Religion, New York, Peter Lang, 1987; Rodney STARK, Laurence IANNACONE, A Supply-Side Reinterpretation of the »Secularization « of Europe, Journal for the Scientific Study of Religion, 33 (1994) 3, 230-252.

${ }^{8}$ Usp. Inglehart, Norris, nav. dj.

${ }^{9}$ Usp. Linda WOODHEAD, Christianity. A Very Short Introduction, Oxford, Oxford University Press, 2004.

${ }^{10}$ Sebastian NĂSTUȚĂ, The Impact of Internet on New Religious Movements' Discourse, Soci- 
kao temeljne suvremene oblike potrage za svetim. ${ }^{11} \mathrm{U}$ prvom je slučaju riječ o institucionalnoj, ritualnoj religioznosti koja ima naglašenu kolektivnu dimenziju. »Traganje« je noviji oblik religioznosti koja je individualizirana, eklektična i otvorena prema različitim, često i međusobno kontradiktornim, religijskim tradicijama. Ovakvu religioznost obilježava otvorenost i nezavršenost, potraga za vlastitošću i poniranje u unutrašnji svemir. Ove se vrste religioznosti mogu analitički razlikovati, iako se često prepliću i prelaze jednu u drugu. Tako se »traganje« može stabilizirati odlukom o čvršćem pripadanju nekoj religijskoj zajednici, a »bivanje« unutar neke religijske zajednice uvijek sadrži mogućnost individualnog traganja i sumnji u ortodoksiju. Bäckström ukazuje na to da se čak i u sekulariziranim skandinavskim zemljama može govoriti o trendu deprivatizacije religije, a uspon konzumerističkog društva - u kojemu se sreća pojedinca povezuje uz pitanja životnog standarda, zdravlja i subjektivnog blagostanja - uzrokuje uspon subjektivističkih vrsta religioznosti ili duhovnosti. Nasuprot racionalističko-prosvjetiteljskim prognozama, egzistencijalna pitanja povezana uz smislenost ljudskog života dolaze u prvi plan. Nastaje razvijeno tržište duhovnih dobara usmjereno na ideje samorazvoja, unutrašnjeg blagostanja i subjektiviteta. ${ }^{12}$ Ove su ideje uvijek otvorene i nedovršene, a postmoderni je identitet fragmentaran jer nepostojanje eksternih referenata i vrijednosna pluralizacija otežavaju izgradnju stabilnih svjetonazora.

Thomas Luckmann ${ }^{13}$ smatra da su do sada postojala četiri društvena oblika manifestacije religije povezanih s pojedinim tipovima društava. U četvrtom obliku, vezanom uz moderna društva, nastaje tzv. nevidljiva religija koja je eklektična, individualizirana i privatizirana. Pojedinci svoj religijski mozaik slažu iz djelića koji dolaze iz raznih religijskih tradicija, pa čak i iz sekularnih ideologija, te individualističkih ideja, poput samorazvoja i samoostvarenja. Ovakva se situacija može pripisati funkcionalnoj diferencijaciji te društvenom pluralizmu koji je posljedica intenzivne komunikacije, tj. rušenja komunikacijskih barijera između različitih religija, društava i kultura.

Imajući u vidu sve navedeno, Casanova ${ }^{14}$ upozorava da se današnja religijska situacija ne može shvatiti u kontekstu teorije sekularizacije ili teorija koje ju osporavaju, nego da sve svjetske religije prolaze kroz proces transformacije

\footnotetext{
ologie Românească, 10 (2012) 4, 63.

${ }^{11}$ Usp. Wade Clark ROOF, Religion and Spirituality. Toward an Integrated Analysis, u: Michelle DILLON (ur.), Handbook of the Sociology of Religion, Cambridge, Cambridge University Press, 2003, 137-150.

${ }^{12}$ Usp. Anders BÄCKSTRÖM, Religion in the Nordic Countries: Between Private and Public, Journal of Contemporary Religion, 29 (2014) 1, 61-74.

${ }^{13}$ Vidjeti, primjerice, Thomas LUCKMANN, The Invisible Religion. The Problem of Religion in Modern Society, New York, MacMillan, 1967; Thomas LUCKMANN, Transformations of Religion and Morality in Modern Europe, Social Compass, 50 (2003) 3, 275-285.

${ }^{14}$ Usp. José CASANOVA, Rethinking Secularization. A Global Comparative Perspective, The Hedgehog Review, Spring \& Summer 2006, 7-22.
} 
uslijed globalizacije te drugih (post)modernizacijskih društvenih i kulturnih promjena. Prema njemu,

»suvremeni je pojedinac osuđen da bira između širokih obrazaca sustava značenja. Iz zapadne monoteističke perspektive, ovakvo stanje politeističke i poliformne individualne slobode možda izgleda novo i postmoderno. Ali iz nezapadne perspektive, osobito iz perspektive azijskih panteističkih tradicija, ovakvo stanje izgleda mnogo više kao staro stanje stvari.«15

S obzirom na izrazitu kompleksnost ovoga teorijsko-istraživačkog pitanja, $\mathrm{u}$ ovome radu nemamo pretenziju doći do definitivnog zaključka može li se u današnjoj situaciji govoriti o rastu, padu ili transformacije religije, nego pitanje transformacije religije koja je uočljiva u nekim, osobito jače moderniziranim zemljama, nastojimo povezati s pitanjem tzv. medijatizacije. Naime, razvoj medijskog tržišta u vremenu globalizacije obilježava nestanak masovnih medija koji nastoje zadovoljiti ukus publike svodeći medijske sadržaje na najmanji zajednički nazivnik. Umjesto toga razvijaju se medijske tržišne niše u kojima se zadovoljavaju individualizirani ukusi koji čine specifične tržišne segmente. Napredak komunikacijskih tehnologija omogućava da takvi tržišni segmenti budu profitabilni. Razvoj religijskih tržišta ili »tržišta simboličkih dobara« dio je ovakvoga razvoja, a ova religijska tržišta omogućavaju stvaranje individualiziranih religijskih mozaika u kojima uloga medija može postajati sve više formativna, a ne samo instrumentalna.

\section{Medijatizacija religije}

Za jednog od rodonačelnika ove teze, danskog istraživača Stiga Hjarvarda, ${ }^{16}$ medijatizacija općenito jest proces u kojemu se različita društvena područja podvrgavaju logici medija, a pod medijatizacijom religije razumijeva raznolike promjene koje nastaju kada mediji, shvaćeni kao kanali, jezik i društveno okružje, mijenjaju oblik i sadržaj religijske komunikacije koja povratno ima važan utjecaj na religijske reprezentacije i poimanje religijskih autoriteta. Tako mediji mogu djelovati na resakralizaciju svijeta fikcijski ili činjenično prikazujući neke religijske, duhovne ili magijske teme, stvarajući ono što Hjarvard naziva »banalnom religijom«. Primjerice, romani i filmovi o Harryju Potteru - uključivanjem fragmenata iz različitih religija i magijskih tradicija, prikazivanjem mitologiziranog i teleološkog svijeta - privlačni su pojedincima koji žele istraživati religijske ideje i reprezentacije mimo teoloških dogmatičnosti i institucionalnih okvira. ${ }^{17}$ Ali medijska reprezentacija religije može djelovati i

\footnotetext{
${ }^{15}$ Isto, 18.

${ }^{16}$ Usp. Stig HJARVARD, The mediatization of religion. A theory of the media as agents of religious change, Northern Lights. Film \& Media Studies Yearbook, 6 (2008) 1, 9-26.

${ }^{17}$ Usp. Laura FELDT, Harry Potter and Contemporary Magic. Fantasy Literature, Popular Cul-
} 
osporavajuće na religijske autoritete stvarajući prostor sekularnih javnih rituala, žalovanja ili promovirajući kultove konzumerizma i slavnih osoba. Stoga se, prema Hjarvardu, teško može govoriti o desekularizacijskom utjecaju medija, čak i onda kada religija postaje sve više medijski prisutna. Naime, prema njemu, religija se u zapadnim sekularnim društvima mora prilagoditi javnom prostoru i nastupati s racionalnim argumentima utemeljenim na znanosti, a ne na religijskim sadržajima. Osim toga, medijatizacija uključuje stvaranje prostora u kojemu je konflikt mišljenja i ideja poželjno stanje, a osporavanje autoriteta njegova neizbježna posljedica. Stoga medijatizacija, po Hjarvardu, pogoduje individualiziranoj religioznosti, odnosno duhovnosti u kojoj je pojedinačna svijest ultimativan referent validacije religijskih istina.

Pokušavajući testirati Hjarvardovu tezu o medijatizaciji, Lövheim i Lundby proveli su longitudinalnu analizu sadržaja norveških dnevnih novina u razdoblju od 20 godina radi utvrđivanja smjera, karaktera i forme prikazivanja religijskih sadržaja. ${ }^{18}$ Njihovi rezultati, ma kako ograničenog geografskog i metodološkog dometa, ukazuju na to da porast količine religijskih sadržaja prati sve jači utjecaj medija na njihovu formu i karakter. Naime, vidljiv je porast novinarskih i uredničkih intervencija koji se očituje u prezentiranju religijskih sadržaja $u$ formi konflikta ili debate, nasuprot rprijašnjem prenošenju autorativnih stavova religijskih čelnika u formi članka ili uvodnika. Njihova analiza pokazuje i primjetan rast pokrivanja manjinskih i alternativnih religija, iako je teško govoriti o povećanom broju sadržaja koji se mogu označiti »banalnom religijom«. Slično tvrdi i Smith analizirajući upotrebu medija na »tržištu simboličkih dobara« u Latinskoj Americi. ${ }^{19}$ Prema njemu, etablirane kršćanske vjerske zajednice, poput katolika, metodista ili luterana, donekle gube utjecaj zbog toga što se putem medija do vjernika probijaju različite vrste religijske heterodoksije. Kako kaže Smith,

»koliko hijerarhije imaju manje moći da nametnu religijsku uniformnost, toliko se i mnogi ljudi osjećaju slobodnim usvojiti naočigled kontradiktorne sustave uvjerenja. Konzumenti simboličkih dobara više se ne osjećaju obveznim prakticirati 'lojalnost brandu' ni neograničeno vjerovati tradicionalnim crkvama. $\aleph^{20}$

Martelli i Cappello, ${ }^{21}$ na tragu Hjarvarda, smatraju da je medijski interes za religijske događaje rezultat ideologije konzumerizma u kojoj su mediji neraz-

ture, and the Representation of Religion, Journal of Contemporary Religion, 31 (2016) 1, 109110.

${ }^{18}$ Usp. Mia LÖVHEIM, Knut LUNDBY, Mediated Religion Across Time and Space. A Case Study of Norwegian Newspapers, Nordic Journal of Religion and Society, 26 (2013) 1, 25-44.

${ }^{19}$ Usp. Dennis A. SMITH, Religion and the Electronic Media in Latin America. A Review by Dennis A. Smith, Prepared for delivery at the 2001 meeting of the Latin American Studies Association, Washington DC, 6.-8. rujna 2001, http://lasa.international.pitt.edu/Lasa2001/ SmithDennis.pdf (21.04.2016).

${ }^{20}$ Isto.

${ }^{21}$ Usp. Stefano MARTELLI, Gianna CAPPELLO, Religion in the Television-mediated Public 
mrsivo povezani s gospodarskim interesima, pri čemu mediji stalno tragaju za simbolikom koja može biti privlačna njihovim konzumentima pružajući smisao individualnoj i društvenoj egzistenciji. Stoga mediji doista mogu doprinijeti paradoksalnom procesu desekularizacije u kojem religija postaje vidljivija i povezanija s drugim društvenim procesima, ali se istovremeno i transformira na različite načine. Martelli i Cappelo navode da medijatizacija religije dovodi do preplitanja sakralnog i profanog koji se susreću u medijskom prostoru i međusobno ga dijele, čime se prostor sakralnog donekle »kontaminira« porukama koje mogu biti u nesuglasju s religijskim doktrinama. ${ }^{22} \mathrm{~K}$ tome, od medijatizacije religije posebno "profitiraju« one religijske zajednice koje imaju centralizirani ustroj, odnosno jednog vođu koji u svakom trenutku može biti prikazan kao simbolička ekspresija dotične religijske zajednice i njezinih vrijednosti, čime se donekle i delegitimiziraju lokalne hijerarhije. Medijatizacija, osobito televizijsko prikazivanje religijskih sadržaja, jače ističu i vidljivije dimenzije religije i religioznog doživljaja, osobito njihovu kolektivno-ritualističku i emocionalnu komponentu, nasuprot individualističkoj pokajničko-asketskoj religioznosti. ${ }^{23}$

$\mathrm{Na}$ tragu ovakvog mišljenja je i Smith ${ }^{24}$ koji, primjerice, smatra da je teleevangelizacija u Latinskoj Americi dovela do odmaka od kartezijanskog poimanja religije prema prilično simplificiranom, ali i dojmljivom i emocionalnom multimedijskom doživljaju donekle usporedivim s doživljajem srednjovjekovnih katedrala. Tako se, prema Smithu, neopentekostalizam u Latinskoj Americi izvrsno prilagodio novoj medijsko-komercijalnoj stvarnosti psihologizirajući religijsku poruku i strogo povezujući evangelizaciju s psihološkim stanjem sreće. Sličnog je mišljenja i Reis koji impresivan rast evangelizma i neopentekostalizma, uz urbanizaciju, sinkretičko prihvaćanje autohtonih latinoameričkih duhovnih tradicija te formalizam i preblizak odnos katoličke hijerarhije s političkim elitama, pripisuje učinkovitom korištenju medija i marketinških alata. ${ }^{25}$ Tako je, primjerice, jedna neopentekostalna religijska zajednica u Brazilu vlasnik jedne od tamošnjih televizijskih mreža. ${ }^{26}$ Sâm uspjeh teleevangelizma može se protumačiti njegovom izravnom naravi koja je dobro prihvaćena od strane ljudi koji sve više informativne i zabavne sadržaje primaju upravo na medijski posredovan način pa se i takva vrsta religijske poruke od strane primatelja doživljava emocionalno intenzivnom i autentičnom, pomalo paradoksalno čak i autentičnijom od poruke licem-u-lice. ${ }^{27}$

\footnotetext{
Sphere Transformations and paradoxes, International Review of Sociology, 15 (2005) 2, 243257.

${ }^{22}$ Usp. isto, 253-254.

${ }^{23}$ Usp. isto, 254.

${ }^{24}$ Usp. Smith, Religion and the Electronic Media in Latin America...

${ }^{25}$ Usp. Raul REIS, Media and Religion in Brazil. The Rise of TV Record and UCKG and Their Attempts at Globalization, Brazilian Journalism Research, 2 (2006) 2, 167-182.

${ }^{26}$ U pitanju je Univerzalna crkva Kraljevstva Božjeg koja je vlasnik televizijske mreže Rede Record, trenutno po prihodima jedne od najvećih svjetskih televizijskih mreža.

${ }^{27}$ Usp. Reis, nav. dj., 175.
} 
Može se reći da Hjarvardov pristup medijatizaciji religije empirijski odgovara društvima u kojim u kojima je sekularizacija neupitan proces, u kojima su mediji nekonfesionalni, u kojima se ljudi primarno oslanjanju na medije prilikom traženja informacija o religiji te u kojima se mogu jasno identificirati institucije koje su osnovni izvor autoriteta kada su religijska vjerovanja i prakse u pitanju. ${ }^{28}$ Dakle, Hjarvardove se tvrdnje trebaju uzeti u svojem specifičnom geografskom, temporalnom i kulturnom kontekstu, a to je sekularizirana sjeverna i zapadna Europa početka 21. stoljeća. Kako naglašava Lynch, drugi društveni i kulturni konteksti mogu se proučavati koristeći Hjarvardov kategorijalni aparat, ali samo kao početno polazište za proučavanje raznolikih načina odnošenja religije i medija.

Nešto oprezniji pristup pojmu medijatizacije nudi Hepp. ${ }^{29}$ Prema njemu je medijatizacija "metaproces" koji podrazumijeva ispreprepletnost medijski posredovane komunikacije sa svakodnevicom i svim drugim društvenim procesima. Ishod ove povezanosti može biti raznolik i ni u kojem slučaju ne podrazumijeva podvrgavanje svih društvenih pojava, između ostalih i religije, neumitnoj medijskoj logici. Medijska tehnologija ima konstitutivan utjecaj na društvene procese čineći stanovit "pritisak« u jednom smjeru, no ovaj utjecaj treba shvatiti tek kao trend ovisan o konkretnom geografskom, društvenom ili kulturnom kontekstu, a nikako kao neumitnu kauzalnost. Slično tomu, Hope Cheong i suradnici u istraživanju religijskog internetskog komuniciranja u Singapuru $^{30}$ pronalaze da su internetske stranice religijskih organizacija pozorno dizajnirani komunikacijski prostori u kojima njihovi voditelji uvelike kontroliraju ovu vrstu komunikacije da bi izgradili i ojačali virtualne i teritorijalne zajednice. Virtualni se prostor stoga ojačava i prostornim naracijama, slikama, zemljopisnim kartama i audiovizualnim materijalima koji naglašavaju prožetost konkretnim lokalitetom i važnost osobnih kontakata. Dvostrani utjecaj medija na status religijskih autoriteta ističe i Campbell. ${ }^{31}$ Prema njoj, internetske religijske prakse uzrokuju osporavanje religijskih autoriteta i nastanak »instant« religijskih stručnjaka koji reinterpretiraju religijske kanone ponekad dolazeći u sukob s religijskim establishmentom. S druge strane, službeni religijski vođe mogu koristiti internet da bi učvrstili svoje vodstvo i kontrolirali aktivnosti pripadnika svoje religijske zajednice. Sličnog je pristupa i Morgan ${ }^{32}$ koji smatra da se medijatizacija samo poseban slučaj medijacije, procesa u kojemu

\footnotetext{
${ }^{28}$ Usp. Gordon LYNCH, What can we learn from the mediatisation of religion debate?, Culture and Religion, 12 (2011) 2, 203-210.

${ }^{29}$ Usp. Andreas HEPP, Cultures of Mediatization, Cambridge, Polity Press, 2012.

${ }^{30}$ Usp. Pauline HOPE CHEONG i dr., The Internet Highway and Religious Communities. Mapping and Contesting Spaces in Religion-Online, The Information Society, 25 (2009) 5, 291-302.

31 Usp. Heidi A. CAMPBELL, Understanding the Relationship between Religion Online and Offline in a Networked Society, Journal of the American Academy of Religion, 80 (2012) 1, 64-93.

${ }^{32}$ Usp. David MORGAN, Mediation or mediatisation. The history of media in the study of religion, Culture and Religion, 12 (2011) 2, 137-152.
} 
se mediji, religijske zajednice, država i akteri građanskog društva angažiraju $\mathrm{u}$ prenošenju religijske poruke u medijskom polju. Ovaj proces, prema njemu, nikako ne znači nužnu dominaciju »medijske logike«, nego može imati različite ciljeve i ishode. Morgan kao primjer navodi britanski protestantski pokret s početka 19. stoljeća u kojemu se religijska poruka širila putem lako dostupnih religijskih publikacija. Taj je pokret bio rezultanta nekoliko sila - vjernika koji su autonomno i iskreno željeli širiti evanđeosku poruku natkonfesionalnim načinom smatrajući tiskanu riječ utjelovljenjem Božje poruke, interesa Britanskog Carstva vođenih »civilizacijskom misijom« te logike samih tiskanih medija, tj. njihove mogućnosti da premosti ogromne teritorijalne udaljenosti.

Ovdje je važno spomenuti i potrebu kontekstualizacije autoriteta i njegova višeslojnog shvaćanja, koju spominje Campbell. ${ }^{33}$ Naime, autoritet nema isto značenje u različitim religijskom tradicijama te se, osim na religijsku hijerarhiju, može odnositi i na pitanja religijskih struktura, ideologija i tekstova. Tako, primjerice, prakticiranje religije online može donijeti promjene u pitanju tko donosi autoritativne odluke u zajednici, no istovremeno pitanja vjerske ideologije i svetih tekstova mogu ostati nedotaknuta i izvan mogućnosti individualne reinterpretacije.

Dakle, komunikacijski mediji, osobito internet, mogu biti i novo sredstvo komunikacije tradicionalnih vjerskih zajednica. Primjerice, Katz ističe da se stav dijela ultrakonzervativnih Haredi Židova prema novim tehnologija korjenito promijenio posljednjih desetljeća. ${ }^{34}$ Od odbijanja konzumacije medija kao navodnih nositelja modernosti i sekularnosti, do njihovog prihvaćanja. Mediji Haredi zajednici nude alternativan način komunikacije i širenja religijskih ideja te produbljuju njihovu izolaciju od mainstream medija. Tako se, primjerice, na internetu nude stranice s religijskim pitanjima i odgovorima, teološkim i etičkim savjetima koje pružaju rabini, virtualne religijske zajednice, lekcije iz Tore i sl. Urednici pri tome djeluju kao svojevrsni gatekeeperi koji filtriraju informacije i onemogućavaju infiltraciju ideja koje se protive religijskoj ortodoksiji. Satelitske televizijske postaje i ilegalne (sic!) radiopostaje djeluju kao dodatni način zaobilaženja mainstream medija i njihova utjecaja. Da bi se spriječio informacijski deficit, pripadnicima Heredi zajednica nude se kratki sažetci tekućih događaja protumačeni u okvirima vjerske optike. ${ }^{35}$ Kako kaže Katz,

»religijski je sektor u Izraelu uspio u korištenju prednosti koje nude progres, istovremeno ih zadržavajući unutar religijskih $\mathrm{i}$ kulturnih okvira«. ${ }^{36}$

\footnotetext{
${ }^{33}$ Usp. Heidi CAMPBELL, Who's Got the Power? Religious Authority and the Internet, Journal of Computer-Mediated Communication, 12 (2007) 1043-1062.

${ }^{34}$ Usp. Yaron KATZ, Technology Use in the Religious Communities in Israel. Combining Traditional Society and Advanced Communications, Journal of Religion, Media \& Digital Culture, 3 (2012) 1, 1-30, http://jrmdc.com (21.04.2016).

${ }^{35}$ Usp. isto, 12.

${ }^{36}$ Isto, 23.
} 
Pri tome je osobito značajno otvaranje prema internetu kao mediju koji je po definiciji decentraliziran i teško ga je kontrolirati, a omogućava pristup najširem rasponu ideja, svjetonazora, pa i načinima ponašanja koje izrazito odstupaju od religijskih normi (npr. konzumacija pornografije). Katzova analiza pokazuje važnost lokalnog konteksta u proučavanju medijatizacije.

$\mathrm{K}$ tomu, religiozni ljudi medijske poruke mogu promatrati i tumačiti pomoću vlastitog interpretativnog okvira. Ova činjenica omogućuje tumačenje rezultata nekih istraživanja iz SAD-a koja govore da, iako su općenito skeptični prema medijima odnosno njihovu sekularizirajućem učinku i navodnom manjku objektivnosti, izloženost medijskim porukama ne uzrokuje to da religiozni ljudi podlegnu »spirali šutnje« i postanu neskloni komunicirati o religiji i iznositi svoja religijska uvjerenja. ${ }^{37}$ Ovakvi se rezultati mogu protumačiti time da religiozni ljudi medije koriste kao produžetak svojih teritorijalnih zajednica, koristeći ih bar dijelom kao alat za njihovo održavanje i učvršćivanje.

\section{Uloga interneta u medijatizaciji religije}

Rastući utjecaj interneta kao medija, a osobito njegova decentraliziranost, zahtijevaju da se uloga interneta u procesu medijatizacije religije posebno analizira. Jedan od vodećih istraživača u ovom polju, Heidi Campbell, smatra da se dosadašnja istraživanja povezanosti interneta i religije mogu podijeliti u tri »vala «. ${ }^{8}$ Prvi je val bio uglavnom deskriptivan, a istraživači su uglavnom nastojali opisati obrasce internetske religijske komunikacije, često vođeni utopijskom idejom »virtualne zajednice«. Drugi val označen je prvim dubljim teorijskim promišljanjima ove teme, a kao najvažnije istraživačko pitanje postaje odnos online i offline zajednica, tj. pitanje kako online participacija može mijenjati tradicionalno poimanje religijske zajednice vezano uz teritorijalnost i osporavati ili redefinirati religijske autoritete. U trećem se valu istraživanja offline i online zajednice ne smatraju međusobno suprotstavljenim, nego se i jedna druga proučavaju u kontekstu širih društvenih procesa koji čine rekonstrukciju svakodnevnih obrazaca društvenosti i u »domestifikaciji« informacijskih i komunikacijskih tehnologija.

Stoga Campbell ističe da se uloga interneta u transformaciji religije može shvatiti samo u okviru transformacije religije koja se događa i u offline svijetu. ${ }^{39}$ Drukčije rečeno, religijske prakse koje se događaju na internetu rezultat su

\footnotetext{
${ }^{37}$ Usp. Mariam F. ALKAZEMI, Students' Spiraling Silence and Willingness to Communicate about Religion in the United States. An Exploration of the Media's Role in Stigmatizing Religion, Journal of Religion, Media E Digital Culture, 2 (2013) 1, 1-27, http://jrmdc.com (21.04.2016).

${ }^{38}$ Usp. Heidi CAMPBELL, Internet and Religion, u: M. CONSALVO, C. ESS (ur.), The Handbook of Internet Studies, Oxford, Wiley-Blackwell, 2011, 232-250.

${ }^{39} \mathrm{C}$ Usp. ampbell, Understanding the Relationship between Religion...
} 
društvenih i kulturnih promjena koje se događaju i u online i u offline svijetu. Prema Cambell, internet dovodi do nečega što se može nazvati umreženom religijom (eng. networked religion) koja ima četiri ključna obilježja: umrežena zajednica, kolažni identiteti, ${ }^{40}$ promjenjivi autoriteti i konvergentne prakse. Sažeto rečeno, navedena obilježja opisuju više ili manje labavu zajednicu pojedinaca koja ne mora imati svoju offline teritorijalnu osnovicu, u kojoj pojedinci autonomno sklapaju vlastite fluidne identitete crpeći materijal iz izvora iz online i offline svjetova raznih religijskih tradicija, a ovaj proces konstrukcije identiteta i religijske prakse službene religijske vođe ne mogu u potpunosti kontrolirati. Internet je nedvojbeno platforma koja pruža više mogućnosti za manje strukturirano oblikovanje religijskih identiteta, nego što je to slučaj s platformama koje nude službene religijske institucije. ${ }^{41}$ Cyberspace sa svojom neograničenošću, kompleksnošću nudi kreativne mogućnosti stvaranja vlastitih religijskih mozaika neograničenih religijskim ortodoksijama. U tom smislu se prosvjetiteljsko-racionalistička i sekularistička uloga medija pokazuje promašenom. Medijatizacija religije nije oruđe sekularizacije, nego zasigurno otvara raznolike transformacijske potencijale koje postmodernu religioznost, bar kada su zapadna društva u pitanju, gura u pravcu individualizma i eklekticizma. Internet ima ogromne komunikacijske mogućnosti koje transcendiraju vrijeme i prostor te brišu razliku između lokalnog i globalnog te time nudi religijsku multufunkcionalnost, inkorporirajući gotovo sve zamislive religijske aktivnosti, poput komunikacije, prozelitizma, informiranja, učenja, religijskog doživljaja i religijske prakse. ${ }^{42}$

Helland religijsku komunikaciju na internetu dijeli na online religiju i religiju online. ${ }^{43} \mathrm{U}$ prvom je slučaju riječ o slobodnom i interaktivnom komuniciranju, a u drugom o ekstenziji offline religijskih zajednica čija je zadaća pružanje informacija, a interaktivnost je u drugom planu. Iako se prva vrsta komunikacije ponajviše vezuje uz neslužbene internetske relgijske zajednice, Helland ističe da se i službene religijske zajednice sve više pretvaraju u online religije usvajajući interaktivno komuniciranje s vlastitim vjernicima, premda su neka istraživa$n_{j a}{ }^{44}$ pokazala da vjernici i dalje preferiraju klasičnu licem-u-lice komunikaciju u usporedbi s online komunikacijom. Stoga se i može reći da, nakon početnog razdoblja impresioniranosti idejom »virtualne zajednice«, istraživači interneta, pa tako i istraživači odnosa medija i interneta, sve jače naglašavaju povezanost

${ }^{40} \mathrm{U}$ originalu: storied identity. Ovaj izraz prevodimo $\mathrm{s} »$ kolažni identitet« jer je riječ o naglašavanju eklektičnosti, individualizacije i fluidnosti u konstrukciji religijskih identiteta u virtualnom svijetu.

${ }^{41}$ Usp. Năstuță, The Impact of Internet on New Religious Movements'..., 65.

${ }^{42}$ Usp. Rosalind I. J. HACKETT, Religion and the Internet, Diogenes, 53 (2006) 3, 67-76.

${ }^{43}$ Usp. Christopher HELLAND, Online Religion as Lived Religion. Methodological Issues in the Study of Religious Participation on the Internet, Online-Heidelberg Journal of Religions on the Internet, 1 (2005) 1.

${ }^{44}$ Usp. Franz FOLTZ, Frederick FOLTZ, Religion on the Internet, Bulletin of Science, TechnologyESociety, 23 (2003) 4, 321-330. 
online i offline veza, tj. ideju da su online veze često sredstvo održavanja postojećih offline društvenih veza i mreža. ${ }^{45}$

Tako i analiza koju su prije nekoliko godina proveli Skoko i Gusić ${ }^{46}$ pokazuje da je prisutnost župa Zagrebačke nadbiskupije na internetu relativno niska, osobito kada se u obzir uzmu evangelizacijsko-formativni sadržaji (molitve, propovijedi, duhovne misli i sl.) te interaktivnost koja je gotovo nepostojeća. Stoga autori i zaključuju da se novi mediji trenutačno ne upotrebljavaju za proaktivno stvaranje virtualnih župnih zajednica, nego su obilježeni pasivnošću i pružanjem rutinskih informacija vezanih uz postojeće zajednice. Kako kažu Campbell i Teusner:

»Kršćani upotrebljavaju ove nove tehnologije kombinirano sa širim kulturnim promjenama u tome kako se religija prakticira u današnjem zapadnom društvu koje dovodi u pitanje tradicionalne religijske vođe, institucije i obrasce religijskog života.« ${ }^{47}$

Dakle, prema Cambell i Teusneru, internet je kompatibilan s već postojećim religijskim promjenama, iako se osporavanje religijskih autoriteta intenzivira s pojavom interneta zbog toga što izaziva dodatnu deteritorijalizaciju religijskih zajednica i mijenja poimanje religijskog identiteta, ali i omogućava alternativne teološke interpretacije i kritički odnos prema postupcima i idejama religijskih vođa i autoriteta.

Reakcija religijskih zajednica na pojavu interneta obično je ambivalentna. ${ }^{48}$ $\mathrm{S}$ jedne se strane ističu prednosti poništavanja vremensko-prostornih granica i mogućnosti širenja religijskih ideja osobama koje bez interneta ne bi došle u kontakt s religijskim porukama. S druge strane, internetski je prostor neograničen i slabo kontroliran te omogućuje utjecaje, osobito na mlade osobe, koji odstupaju od religijskih poruka. Kao i svi drugi mediji, internet može djelovati i izolirajuće jer se gubi neposredan ljudski kontakt, a time i empatija i osjećaj solidarnosti s drugim ljudskim bićima i članovima zajednice.

Kao jedan od primjera ovih dvojbi može se uzeti poruka pape Franje objavljena 21. siječnja 2016. godine povodom Svjetskog dana komunikacija u kojoj je internet i društvene mreže nazvao »Božjim darovima« jer šire prostor komunikacije, dijaloga i tolerancije, ali je istovremeno upozorio i na odgovornost prilikom njihove upotrebe, ističući da je online komunikacija ponešto manje »realna« od komunikacije licem-u-lice, da brzina događanja na društvenim

\footnotetext{
${ }^{45}$ Primjerice L. L. Dawson, Religion and the quest for virtual community, u: L. L. DAWSON, D. E. COWAN (ur.), Religion Online. Finding Faith on the Internet, New York, Routledge, 2004, 7589; Knut LUNDY, Patterns of Belonging in Online/Offline Interfaces of Religion, Information, Communication \& Society, 14 (2011) 8, 1219-1235.

${ }^{46}$ Usp. Božo SKOKO, Valentina GUSIĆ, Novi mediji u službi evangelizacije i u životu župne zajednice - primjena u župama Zagrebačke nadbiskupije, Nova prisutnost, 11 (2012) 2, 193-214.

${ }^{47}$ Heidi A. CAMPBELL, Paul Emerson TEUSNER, Religious Authority in the Age of the Internet, 2011, 63; www.baylor.edu/content/services/document.php/130950.pdf (21.04.2016).

${ }^{48}$ Usp. isto.
} 
mrežama često oduzimaju nužno vrijeme za individualnu samorefleksiju te da upotreba društvenih medija može udaljiti pojedince od njihovih obitelji i prijatelja. Ovakva je poruka posve na tragu prijašnjih poruka pape Benedikta XVI. koje su bile vrlo afirmativne, ali i kritične i upozoravajuće. ${ }^{49}$ Primjerice, $u$ poruci izdanoj u povodu Svjetskog dana komunikacija 2013. godine papa ističe izraziti evangelizacijski potencijal društvenih mreža, ali ističe i da je učinkovitost i utjecaj poruka koje se njima šire često više pod utjecajem površne popularnosti, nego njihove intrinzične valjanosti i vrijednosti.

\section{Zaključak}

Naše je mišljenje da je medijatizacija religije potaknuta društvenim procesima, ali i da dodatno potiče specifičan duhovni pluralizam i individualizam (post)modernih zapadnih društava u kojemu nastaju nove, eklektične forme duhovnosti. Medijatizacija religije dobro ilustrira promašene rasprave koje su se posljednjih desetljeća vodile oko teorije sekularizacije. U njima su se sukobljavala teorijska pretjerivanja zagovornika teorije(a) sekularizacije i njezinih nezasluženih osporavanja. Zagovornici sekularizacije tako nude prognoze iz rakursa teorije modernizacije koje nude linearnu viziju povijesti i posve zanemaruju lokalni kulturološki i civilizacijski kontekst. S druge strane, kritičari teze o sekularizaciji svako javno manifestiranje religije i religioznosti vide kao nedvojben dokaz da je sekularizacija mit. Može se reći da su se jače verzije teorije sekularizacije i njihove prognoze, koje su predviđale izrazit pad, pa čak i potpun nestanak, religioznosti, pokazale promašenim. Iako se u zapadnim društvima može govoriti o sekularizaciji na razini strukturalne diferencijacije, religioznost ne nestaje nego se donekle mijenja njezina društvena forma. Postmoderno društvo obilježava pad povjerenja u velike ideologije i neupitne autoritete, a ovakva se duhovna situacija odražava i na područje religije. U njemu je sve manje »bivanja«, sve više »traganja«, vođenog željom za individualnom autentičnošću u kojoj se religijske postavke i iskustvo validiraju na individualnoj razini.

Medijatizacije religije s jedne strane ukazuje na živost religije i tržišta simboličnih dobara, no s druge strane ukazuje i na činjenicu da se medijski posredovana poruka mijenja i da se religija pluralizira i demonopolizira. Dakle, medijatizacija s jedne je strane rezultat religijske transformacije koja uzrokuje promjenjive oblike autoriteta i prakticiranja religije, a s druge je strane i čimbenik koji dodatno potiče takve religijske promjene, pri čemu izaziva i dodatne transformacije religije. Medijatizacija nije samo refleksija transformacije religije u offline svijetu, nego je i proces u kojemu se religija transformira u skladu

\footnotetext{
${ }^{49}$ Sve se poruke Benedikta XVI. mogu naći na službenoj internetskoj stranici Svete Stolice: http:// w2.vatican.va/content/benedict-xvi/en/messages/communications.index.html\#messages.
} 
sa zakonitostima medijskog jezika i medijskog okružja i prilagođava im se. Ovakav proces, kako smo istaknuli, izaziva dodatne promjene kada su u pitanju konstrukcija religijskih identiteta i odnos prema religijskim autoritetima, ali i može više pogodovati jednim, a manje drugim religijskim zajednicama. Pri tome se važnost i doseg ovih promjena ne trebaju prenaglašavati jer medijsko posredovanje religije u mnogim situacijama služi samo kao pojačavanje postojećih teritorijalnih, licem-u-lice religijskih zajednica te se nalazi pod kontrolom formalnih religijskih vođa.

\section{Željko Pavić" \\ Mediatization of religion in the context of religious transformation Summary}

In this paper the author tries to put the current mediatization thesis into the framework of theories that aim to explain position of religion and religiosity in the contemporary societies. Contemporary situation is explained within the context of religious transformation, and the author has made an attempt to analyze the influence of the mediatization on the aforementioned context. In that way, mediatization is conceptualized as a process that is influenced by the transformation of religion, but also at least partially as a process that advances the religious transformation by encouraging the development of spiritual pluralism and individualism of (post)modern Western societies wherein new and eclectic forms of religiosity begin to appear. In that sense, a particular effort has been made in order to explain the influence of mediatization on the religious authorities and to analyze the Internet as a new media that arguably has a strong effect on the transformation of religion and religious authorities. The author concludes that mediatization is a very complex and two-sided process whose influence and impact should not be over-emphasized since in many situations media-conveyed religion serves only as a magnifier of the existing territorial face-to-face religious communities, controlled by the formal religious authorities.

Key words: mediatization, transformation of religion, secularization, Internet, socio-cultural changes.

(na engl. prev. Željko Pavić)

\footnotetext{
* Željko Pavić, PhD, Assistant Professor, Department of Cultural Studies at Josip Juraj Strossmayer University of Osijek; Address: Trg Svetog Trojstva 3, HR-31000 Osijek, Croatia; E-mail: zpavic@kulturologija.unios.hr.
} 